\title{
OS ENCONTROS DE SERVICO DE DEFICIENTES VISUAIS EM INSTITUIÇÕES DE ENSINO SUPERIOR
}

\section{SERVICE ENCOUNTERS OF VISUALLY IMPAIRED IN HIGHER EDUCATION INSTITUTIONS}

\author{
Pedro Felipe da Costa Coelho \\ pedrofelipecc@gmail.com \\ Universidade Federal da Paraíba (UFPB), João Pessoa/PB, BRASIL
}

\author{
Anna Carolina Rodrigues Orsini \\ carolorsini@hotmail.com \\ Universidade Federal da Paraíba (UFPB), João Pessoa/PB, BRASIL
}

\section{Nelsio Rodrigues de Abreu}

nelsio@gmail.com

Universidade Federal da Paraíba (UFPB), João Pessoa/PB, BRASIL

\begin{abstract}
Resumo
Este artigo objetiva compreender a avaliação dos alunos com deficiência visual sobre os encontros de serviço com funcionários de secretaria e professores em Instituições de Ensino Superior. Foram realizadas 10 entrevistas semiestruturadas face-a-face com estudantes universitários deficientes visuais. Os dados foram coletados através da Técnica do Incidente Crítico e analisados por meio da análise de conteúdo. Dentre os resultados, constatouse que a avaliação negativa dos alunos é um processo iniciado durante a matrícula e reforçado durante os demais encontros de serviço. Também foi observado que os avanços na legislação e o aumento do número de matrículas não garantem a inclusão desses alunos em IES, visto que as experiências de vulnerabilidade de consumo resultaram da falta de capacitação e do preconceito de funcionários de secretária e professores, que confundiram a deficiência visual com as demais deficiências e aumentaram as notas dos alunos sem justificativa, respectivamente.
\end{abstract}

Palavras-chave: Vulnerabilidade do Consumidor. Consumidores com Deficiência. Deficiente Visual. Encontros de Serviço.

\begin{abstract}
The paper has the objective to understand the appreciation of students with visual disabilities about service encounters with secretariat staff and professors in Higher Education Institutions. 10 semi-structured interviews face-to-face were conducted with visually impaired university students. Data were collected through the Critical Incident Technique and analyzed according to the content analysis. It was concluded that the negative valuation of the students is a process begun during the enrollment of students and enhanced in others service encounters. It was also noted that advances in legislation and increased enrollment does not guarantee the students inclusion in HEIs because consumer vulnerability experiences resulted from lack of training and prejudgment of the secretariat staff and professors, who mistook visual impairment with other disabilities and increased the scores of students with disabilities without justification, respectively.
\end{abstract}

Keywords: Consumer Vulnerability. Consumers With Disabilities. Visually Impaired. Service Encounters. 


\section{Contextualização}

A pesquisa em marketing é repleta de áreas temáticas que possuem abordagens distintas entre si e refletem os anseios dos gestores organizacionais em aprimorar suas decisões mercadológicas. Com efeito, estes estudos apresentam valiosas contribuições para as organizações, mas, em sua grande maioria, desconsideram as implicações sociais da atividade de marketing para a sociedade. A fim de trazer esta discussão para a prática e a teoria em marketing, a subdisciplina de Marketing e Sociedade foi criada e pode ser considerada uma área promissora para mitigar a imagem negativa do marketing perante a sociedade, tendo em vista o seu enfoque na promoção de bem-estar social.

Uma das linhas de pesquisa de Marketing e Sociedade questiona a exploração de indivíduos vulneráveis no momento da interação no mercado de compra. Argumenta-se que determinados grupos de pessoas são constantemente incapazes de atingir suas metas em situações de consumo e, portanto, espera-se que os profissionais de marketing assegurem que tais consumidores não sejam explorados na interação mercado-consumidor diante da impotência que apresentam (BAKER, 2006; SILVA, 2011). Esta linha de pesquisa é denominada de Vulnerabilidade do Consumidor e, a partir da definição apresentada, as Pessoas com Deficiência (PcD) são consideradas consumidores vulneráveis, devido às limitações que apresentam.

No Brasil, as PcD correspondem a aproximadamente $23,9 \%$ da população, o que representa 45,6 milhões de pessoas com deficiências físicas, sensoriais, mentais ou múltiplas. O Nordeste é a região com a maior proporção de $\mathrm{PcD}(26,63 \%)$ e a Paraíba é o segundo estado que apresenta o maior número de deficientes (27,76\%). Em relação aos diferentes tipos de deficiência, a prevalência variou de acordo com a sua natureza. A deficiência visual apresentou a maior ocorrência, afetando 18,6\% da população (IBGE, 2010).

Diante da representatividade de PcD no Brasil, nos últimos anos têm aumentado a preocupação por parte da sociedade brasileira em proporcionar uma educação de qualidade a todas as pessoas, incluindo as PcD. Contudo, para terem seus direitos garantidos, um longo caminho foi percorrido, que foi da segregação educacional - atendimento em instituições especializadas ou classes especiais em escolas regulares - (MANTOAN, 2003) até chegar à atualidade, onde se busca a sua inclusão nas instituições de ensino regulares.

Apesar da representatividade de $\mathrm{PcD}$ na população brasileira e do direito que possuem em atuar como consumidoras, inclusive dos serviços educacionais, grande parte das publicações em periódicos de Administração que tratam deste grupo de pessoas são contribuições estrangeiras (BAKER; STEPHENS; HILL, 2001; HOGG; WILSON, 2004; GOODRICH; RAMSEY, 2012). No entanto, algumas publicações nacionais da última década sobre $\mathrm{PcD}$ retratam sua atuação como consumidoras (FARIA; MOTTA, 2012; DAMASCENA; FARIAS, 2013; DAMASCENA, 2014; MANO, 2014). A publicação dessas recentes pesquisas contribui para mobilizar os analistas de marketing a entender quais são necessidades de consumo de $\mathrm{PcD}$, uma vez que persiste no Brasil um desinteresse por parte de acadêmicos e praticantes do campo da Administração em analisar o grupo nas diversas perspectivas possíveis (FARIA et al., 2014).

A despeito da dificuldade em agir como consumidoras e do desinteresse dos acadêmicos em estudá-los (PINTO, FREITAS, 2011), os deficientes visuais atuam em diversos setores empresariais e contratam diferentes prestadoras de serviços, como as Instituições de Ensino Superior (IES). De fato, o ensino é uma atividade de destaque no setor de serviços no Brasil e as características típicas do Marketing de Serviços estão presentes nas instituições educacionais, e nomeadamente nas IES. As mudanças no ambiente educacional têm levado as organizações a adotar sistema de gestão cujo principal objetivo é satisfazer, com qualidade, as necessidades dos alunos cada vez mais exigentes (MOREIRA et al., 2011).

Em relação ao atendimento escolar oferecido ao deficiente visual, melhores práticas pedagógicas que possam auxiliar na inclusão de alunos que dependem de apoio especial para avançar no seu processo de escolarização (LEITE; SILVA, 2006). De acordo com Diaz et al. (2009), o aluno com deficiência visual não é incapaz de aprender, porém, precisa de certo cuidado na metodologia da aula, didática do professor e a acessibilidade aos materiais complementares.

Em relação ao atendimento escolar oferecido ao deficiente visual, melhores práticas pedagógicas têm 
sido desenvolvidas e aprimoradas para auxiliar esse grupo de alunos (LEITE; SILVA, 2006). O aluno com deficiência visual não é incapaz de aprender, porém precisa de certo cuidado na metodologia da aula, didática do professor e a acessibilidade aos materiais complementares (DIAZ et al., 2009). Além disso, somente a legislação não é suficiente para que a inclusão dos alunos com deficiência visual seja de fato uma realidade no contexto nacional, pois é necessária a mudança de postura dos professores, dos pais e da comunidade escolar em geral (SÁ, 2000).

Diante do cenário apresentado, o presente estudo possui o objetivo de compreender a avaliação dos alunos com deficiência visual sobre os encontros de serviço com funcionários de secretaria e professores em Instituições de Ensino Superior (IES). Para o alcance do objetivo geral, os seguintes objetivos específicos foram traçados: (1) investigar as ações inclusivas e exclusivas das IES voltadas para alunos com deficiência visual; (2) caracterizar os encontros de serviços entre alunos e professores/funcionários de secretaria; (3) descrever a vulnerabilidade de consumo dos alunos com deficiência visual em IES.

\section{Vulnerabilidade do consumidor e 0 deficiente visual}

A vulnerabilidade do consumidor ocorre quando as pessoas estão em desvantagem durante as relações de troca, devido às características que não são amplamente controláveis por eles no momento da transação (ANDREASEN; MANNING, 1990). Desse modo, cria-se uma dependência de fatores externos para criar equidade no mercado (BAKER; GENTRY; RITTENBURG, 2005; SHULTZ; HOLBROOK, 2009). É ressaltado que a vulnerabilidade não é uma característica que o consumidor quer possuir ou não possuir, mas pode haver uma propensão maior ou menor de um consumidor à vulnerabilidade em relação a outros consumidores em situações similares. Neste caso, pode-se identificar a presença de alguns grupos de indivíduos com tendências mais expressivas a experimentarem uma situação de vulnerabilidade (JONES; MIDDLETON, 2007), como as PcD.

Destarte, o modelo conceitual clássico foi desenvolvido para aprimorar compreensão da experiência de vulnerabilidade do consumidor. No modelo de Baker et al. (2005) foi afirmado que (1) as características biofísicas e psicossociais, (2) os estados de luto, humor, transição e motivação e (3) as condições externas, como problemas estruturais ou elementos sociais, aumentam a chance de um indivíduo experimentar vulnerabilidade. Dentre os elementos sociais que colaboram a vulnerabilidade de consumo, destacamse a estigmatização ou discriminação do mercado perante um grupo de consumo.

Em relação aos conceitos de estigmatização e discriminação, muitas vezes são às pessoas imputadas características que nem sempre são reais. Em algumas situações, surgem evidências de que a outra pessoa possui um atributo que o torna diferente dos outros - um estigma - e esse indivíduo passa a não ser aceito plenamente na sociedade - sofre a estigmatização -, devido ao estigma que apresenta. Já a discriminação ocorre quando há uma atitude adversa perante uma característica específica de uma pessoa, como a raça, gênero, orientação sexual, nacionalidade, religião etc. (GOFFMAN, 1988). Contudo a discriminação e o preconceito, por si só, não devem ser confundidos com a vulnerabilidade de consumo, muito embora possam contribuir fortemente para este processo (DAMASCENA, 2014).

Diante do exposto, as pessoas com deficiências físicas, sensoriais, mentais ou múltiplas podem ser consideradas vulneráveis enquanto consumidoras, devido às próprias características que apresentam. Entretanto, tal constatação é atrelada a uma visão biomédica de $\mathrm{PcD}$ e desconsidera o contexto em que a deficiência se configura. De acordo com a World Health Organization (WHO), agência das Nações Unidas que atua especialmente na saúde pública internacional, a concepção inicial sobre pessoas com deficiência era relacionada aos conceitos de impairment (deficiência), disability (incapacidade) e bandicap (desvantagem) (WHO, 2002). A evolução para um modelo social define deficiência como "uma interação dinâmica entre problemas de saúde e fatores contextuais, tanto pessoais quanto ambientais" (OMS, 2011, p. 4). Desse modo, a deficiência passa a entendida como um problema socialmente criado pelo ambiente físico, provocada por atitudes de outros e características do ambiente social (THOMAS, 2004) que impedem a plena e efetiva participação dessas pessoas na sociedade em igualdade de oportunidades com as demais pessoas (OMS, 2011). 
Essa nova perspectiva passa a considerar PcD como consumidores vulneráveis não apenas em função de suas características físicas, mas também se tornam vulneráveis socialmente devido às condições externas (BARNES; MERCER, 2003; BAKER; GENTRY; RITTENBURG, 2005). De fato, as dificuldades enfrentadas pelas PcD começam em aspectos básicos para a formação de qualquer pessoa, com a falta de educação especializada. Professores sem nenhuma espécie de preparo e a falta de equipamentos adequados fazem com que a maioria dos deficientes não tenha acesso à educação (MANENTE; RODRIGUES; PALAMIN, 2007).

Em relação aos deficientes visuais, o Decreto $n^{\circ} 5.296$ de 2 de dezembro de 2004 considera a deficiência visual como: cegueira, na qual a acuidade visual (aquilo que se enxerga a determinada distância) é igual ou menor que 0,05 no melhor olho, com a melhor correção óptica; a baixa visão, que significa acuidade visual entre 0,3 e 0,05 no melhor olho, com a melhor correção óptica; os casos nos quais a somatória da medida do campo visual (amplitude da área alcançada pela visão) em ambos os olhos for igual ou menor que $60^{\circ}$; ou a ocorrência simultânea de quaisquer das condições anteriores não passíveis de melhora na visão com terapêutica clinica ou cirúrgica. A Fundação Dorina Nowill, por sua vez, define deficiência visual como "a perda total ou parcial, congênita (genética, por exemplo) ou adquirida (caso dos traumas oculares), da visão de ambos os olhos" (FUNDAÇÃO DORINA NOWILL, 2012, p. 6).

Os deficientes visuais, portanto, são vulneráveis em situações de consumo devido às características físicas que apresentam e devido ao ambiente social em que estão inseridos. Apesar de qualquer indivíduo, dependendo do contexto de consumo, poder vivenciar experiências de vulnerabilidade, tais indivíduos estão constantemente suscetíveis a situações de desequilíbrio. A adaptação da estrutura física dos ambientes, como a complementação de escadas por rampas e elevadores e a construção de banheiros acessíveis por si só não proporciona a inclusão de deficientes visuais (PAVIA; MASON, 2014), uma vez que os varejistas não se encontram preparados para lidar com tal públicoalvo (KAUFMAN-SCARBOROUGH, 2001) e os prestadores de serviços são incapazes de percebêlos como consumidores (BAKER; HOLLAND; KAUFMAN-SCARBOROUGH, 2007)
Com o objetivo de apresentar discussões acadêmicas sobre a prestação de serviços educacionais para $\mathrm{PcD}$, o tópico seguinte irá tratar dos serviços educacionais de IES, abordando ainda a educação inclusiva.

\section{Serviços educacionais das IES}

Em anos recentes, o marketing tem atraído a atenção de reitores, presidentes, diretores de escolas e profissionais diversos relacionados à educação. Muitos estão interessados em saber como as ideias de marketing podem ser relevantes para os problemas que enfrentam, tais como: (1) atrair alunos melhores e em maior quantidade; (2) aumentar a satisfação destes alunos com a instituição; (3) planejar programas que refletem a missão da instituição; e (4) atrair entusiasmo de ex-alunos e outros segmentos da comunidade (FROEMMING, 2001). Diante desse cenário, as IES reconhecem cada vez mais a importância do conhecimento em marketing para descobrir novos mercados-alvo, conforme a oferta de serviços oferecidos pelas organizações.

O serviço educacional é constituído de ações intangíveis, dirigido à mente das pessoas, de entrega contínua, realizado através de uma parceria entre a organização de serviço e os alunos, e, apesar de ter um alto contato pessoal com o cliente, é de baixa customização (LOVELOCK, 1983). Contudo, os estudos sobre gestão da qualidade nas IES focam na "educação" e esquecem outros fatores que influenciam a percepção do aluno. Outro aspecto a ser considerado ao se tratar de qualidade de serviços de ensino superior, é que o aluno (cliente) deve ser visto como um participante ativo do processo de aprendizagem ao invés de um simples produto (resultado final), e as dimensões da qualidade podem variar de acordo com os seus interesses particulares, uma vez que o aluno, no momento em que entra em contato com a instituição, começa a receber estímulos que são processados, formando, assim, sua avaliação pessoal da qualidade global do serviço educacional (DUTRA et al., 2002).

As instituições de ensino também devem ser capazes de determinar as necessidades, desejos e interesses de seus consumidores e adaptar-se para entregar satisfações que preservem ou enriqueçam o bem estar e interesses em longo prazo desses 
consumidores e da sociedade (KOTLER; FOX, 1994). De fato, uma educação de qualidade não pode ser construída por sistemas educacionais constituídos por estruturas burocráticas, lentas e centralizadoras e que não permitem agilidade na solução de problemas (XAVIER, 1996). Dentre os problemas evidenciados no contexto nacional, destaca-se a dificuldade das IES de oferecer um ensino de qualidade para pessoas com deficiência, uma vez que as iniciativas voltadas para a educação inclusivas não são eficazes (LIZOTE; VERDINELLI, 2012).

O entendimento sobre inclusão não diz respeito somente às pessoas com deficiência, mas a todos da sociedade, enquanto cidadãos com direito de igualdade e acesso aos recursos disponibilizados (MANTOAN, 2003). E em relação à educação inclusiva de deficientes visuais, há diversas barreiras a serem enfrentadas pelos alunos brasileiros em IES.

A reclamação mais constante desses alunos diz respeito à disponibilização do material didático em tempo hábil para a realização das atividades propostas pelos professores, uma vez que para os alunos com deficiência são mantidas as mesmas datas para a entrega das atividades. Neste sentido, os alunos com deficiência visual ficam em desvantagem, já que, para esses, a obtenção do material definido para a tarefa depende de outros procedimentos como scanner, programas de computador adequados, o que, muitas vezes, requer a ajuda de outras pessoas, que nem sempre estão disponíveis no tempo necessário (LEITE; SILVA, 2006).

Além da disponibilização dos materiais didáticos, a qualidade da oferta dos serviços educacionais está diretamente relacionada aos encontros de serviço dos alunos com os colaboradores da IES. O tópico seguinte abordará a avaliação dos encontros de serviço, com ênfase para o consumidor deficiente visual em IES.

\section{A avaliação dos encontros de serviço em IES}

O encontro de serviço representa séries de interações e transações nas relações entre empresa e cliente. Em alguns casos, a experiência de serviço pode ser reduzida a um único encontro, com o pedido, o pagamento e a execução da entrega ocorrendo no mesmo lugar (PAYNE et al., 2008). Em outros casos, como o de serviços educacionais, a experiência do cliente abrange uma sucessão de encontros que pode se distribuir por um longo período de tempo, envolver vários funcionários e até acontecer em lugares distintos. À medida que aumenta o nível de contato do cliente com a prestação de serviço, tende a haver encontros de serviço mais numerosos e demorados (BATTAGLIAA; BORCHARDT, 2010).

Em relação à avaliação dos encontros de serviço, Bitner (1990) analisou a satisfação dos consumidores nos encontros de serviço e desenvolveu um modelo que trata da "desconfirmação de expectativas", pressupondo que as expectativas são comparadas com o desempenho do serviço. Desse modo, caso as expectativas sejam superiores ao desempenho, haverá insatisfação; se as expectativas são atingidas, ou a performance superá-las, resultará satisfação. Portanto, argumentou-se que há uma estreita relação entre satisfação nos encontros de serviço e a qualidade percebida do serviço (PARASURAMAN et al.,1985; BITNER, 1990).

Contudo, ressalta-se que tanto o cliente quanto o prestador de serviços dependem quase que exclusivamente de sinais observáveis e estereótipos para formar expectativas sobre o encontro e avaliar seu sucesso ou fracasso (JOHNSON et al., 2013). Desse modo, o encontro de serviço pode ser avaliado de maneira negativa pelo consumidor, caso o prestador de serviço exponha ao consumidor as expectativas negativas que possui sobre esse indivíduo (BARKER; HÄRTEL, 2004). Por exemplo, um consumidor deficiente visual pode avaliar negativamente um encontro de serviço com um vendedor em uma loja de vestuário, caso esse vendedor forme expectativas negativas sobre o consumidor com deficiência e pressuponha que esse consumidor não leva em consideração a cor da roupa de uma camisa na sua tomada de decisão.

Em relação à avaliação dos encontros de serviços em IES, diversos problemas são relatados pelos alunos com deficiência. Na percepção desses consumidores, a maioria das IES os recebe apenas por força da lei e que mesmo aquelas que estão sensíveis a essa causa, não estão preparadas para recebê-los de maneira adequada (LEITE; SILVA, 2006). Outro grupo de alunos deficientes auditivos relatou que os preceitos da na Lei de Diretrizes e Bases da Educação Nacional 
são parcialmente atendidos, pois segundo consta as instituições, além de possuir um trabalho pedagógico específico que atenda ao portador da deficiência, devem contar com professores capacitados. $\mathrm{E}$ isto não foi identificado de maneira integral no estudo desenvolvido (LIZOTE; VERDINELLI, 2012).

Sabe que o processo de ensino-aprendizagem da pessoa com deficiência visual requer uma adaptação de estratégias, recursos e materiais específicos, além de capacitação profissional para que tenha acesso a todos os conteúdos, às atividades propostas e sintase incluída em seu meio escolar. Desse modo, os professores são responsáveis por: (1) incluir o aluno deficiente visual em todas as atividades, fazendo adaptações quando necessário; (2) aplicar as mesmas regras de disciplina ao aluno com deficiência visual, que são aplicadas aos demais alunos; e (3) nomear, explicar, descrever de forma objetiva imagens, cenas e situações, além de descrever os registros feitos no quadro, e não apenas apontá-los (LEITE, 2009).

Os professores e funcionários de secretaria, ao tratar da inclusão de deficientes visuais, também devem compreender que o aluno cego ou com baixa visão precisará de recursos adaptados para que consiga realizar atividades dentro ou fora da escola. Dentre os materiais básicos para o processo de ensinoaprendizagem do aluno cego, a reglete e punção, o sorobã, textos transcritos em Braille e gravador são essenciais. Caso seja necessário, o aluno poderá utilizar a máquina de escreverem Braille (Perkins) e alguns recursos eletrônicos, como calculadoras falantes, computadores com sintetizador de vOz, impressoras Braille e scanner de mesa (LEITE, 2009).

A partir do exposto, percebe-se que os alunos com deficiência visual são consumidores que, por diversos motivos, podem vivenciar situações de vulnerabilidade de consumo em IES. As instituições de ensino superior devem ser capazes de receber e incluir pessoas com necessidades distintas, mas, em alguns casos, são avaliadas negativamente pelos alunos, uma vez que não possuem estrutura adequada e pessoas preparadas para auxiliá-los no processo de aprendizagem. Os funcionários de secretaria e os professores lidam diariamente com os alunos, por isso foram analisados neste estudo.
A seguir os procedimentos metodológicos são apresentados, seguidos dos resultados e das considerações finais.

\section{Procedimentos metodológicos}

A pesquisa é caracterizada como interpretativa básica de caráter descritivo (MERRIAM, 2009). Para o alcance do objetivo proposto, os dados foram coletados através da Técnica do Incidente Crítico (TIC), onde um processo de classificação é realizado para a análise de conteúdo de histórias ou incidentes críticos (FLANAGAN, 1954; BITNER, 1990). Tratase de uma técnica apropriada para se descobrir as fontes de satisfação e de insatisfação nos encontros de serviços, pois os respondentes são chamados a contar histórias e lembrar eventos, algo que a maioria das pessoas faz muito facilmente (FROEMMING, 2001). É ressaltado, ainda, que no presente estudo a TIC foi adotada através de uma abordagem qualitativa, onde se objetiva descobrir e entender um fenômeno, um processo ou perspectivas e visões de mundo das pessoas envolvidas (MERRIAM, 2009).

Em relação à coleta dos dados, foram realizadas 10 entrevistas semi-estruturadas face-a-face com estudantes de universidades públicas e particulares de João Pessoa que possuem perda total ou parcial da visão. A definição dos sujeitos de pesquisa foi feita por conveniência e as entrevistas foram gravadas em meio digital e transcritas na íntegra. A tabela a seguir apresenta a descrição dos entrevistados. 
Tabela 1. Perfil dos entrevistados

\begin{tabular}{|c|c|c|c|c|c|c|}
\hline Pseudônimo & Idade & Sexo & $\begin{array}{c}\text { Tipo de } \\
\text { Deficiência Visual }\end{array}$ & $\begin{array}{c}\text { Há quanto tempo é } \\
\text { deficiente }\end{array}$ & $\begin{array}{l}\text { Tipo de } \\
\text { IES }\end{array}$ & $\begin{array}{c}\text { Curso/ } \\
\text { Semestre }\end{array}$ \\
\hline Ana & 19 & Feminino & Totalmente Cega & Congênita & $\begin{array}{l}\text { Pública } \\
\text { Federal }\end{array}$ & Economia $/ 2^{\circ}$ \\
\hline Bruna & 24 & Feminino & Totalmente Cega & Congênita & $\begin{array}{l}\text { Pública } \\
\text { Federal }\end{array}$ & Direito $/ 4^{\circ}$ \\
\hline Cláudia & 31 & Feminino & Totalmente Cega & Aos 13 anos & Particular & Pedagogia $/ 7^{\circ}$ \\
\hline Diana & 28 & Feminino & $\begin{array}{c}\text { "Praticamente sem } \\
\text { visão" }\end{array}$ & Aos 3 anos & $\begin{array}{l}\text { Pública } \\
\text { Federal }\end{array}$ & Jornalismo $/ 9^{\circ}$ \\
\hline Elena & 22 & Feminino & Totalmente Cega & Congênita & $\begin{array}{l}\text { Pública } \\
\text { Estadual }\end{array}$ & Direito $/ 1^{\circ}$ \\
\hline Fernanda & 19 & Feminino & Cega de um olho & Congênita & $\begin{array}{l}\text { Pública } \\
\text { Federal }\end{array}$ & História $/ 2^{\circ}$ \\
\hline Gustavo & 27 & Masculino & Totalmente Cego & Congênita & Particular & $\begin{array}{l}\text { Publicidade e } \\
\text { Propaganda } / 5^{\circ}\end{array}$ \\
\hline Hugo & 23 & Masculino & $\begin{array}{l}\text { Perda parcial da } \\
\text { visão: pequena } \\
\text { percepção luminosa }\end{array}$ & Aos 11 anos & $\begin{array}{l}\text { Pública } \\
\text { Federal }\end{array}$ & Engenharia Mecânica $/ 4^{\circ}$ \\
\hline Iogo & 41 & Masculino & Totalmente Cego & Congênita & $\begin{array}{l}\text { Pública } \\
\text { Federal }\end{array}$ & Direito $/ 8^{\circ}$ \\
\hline João & 28 & Masculino & Totalmente Cego & "Desde bebê" & Particular & Administração $/ 6^{\circ}$ \\
\hline
\end{tabular}

Fonte: Elaborado pelos autores.

Como é observado na tabela 1, todos os entrevistados são estudantes de IES públicas ou privadas e objetivouse equilibrar a amostra em sexo e tipo de IES. As entrevistas tiveram duração média de 29 minutos, totalizando 64 laudas, e foram realizadas pelo primeiro autor do estudo. Como observado por Faria (2010), a condução de pesquisas com deficientes visuais é dificultada pela incredulidade dos sujeitos da pesquisa na importância dos estudos científicos. Dessa maneira, o acesso aos dez participantes do estudo foi facilitado pelo contato inicial com o Instituto dos Cegos da Paraíba Adalgisa Cunha, instituição filantrópica que há 70 anos atua na alfabetização, educação artística e física de deficientes visuais, além de oferecer serviços de transcrição para o Braille e reabilitação visual para pessoas com baixa visão.

Neste ensejo, as duas primeiras entrevistas foram realizadas na própria instituição, uma vez que as entrevistadas - Bruna e Elena - atuam na ONG. As demais ocorreram nas IES dos alunos, geralmente no intervalo de suas aulas. As falas obtidas durante as entrevistas foram transcritas e classificadas por meio da análise de conteúdo (Bardin, 2006). Não houve nenhuma determinação prévia das categorias, buscando classificá-las de maneira progressiva. Seguindo as recomendações de Merriam (2009), a seleção da amostra foi encerrada quando as categorias que explicavam o fenômeno estudado emergiram com consistência.

\section{Apresentação e análise dos resultados}

Esta seção apresenta os resultados da etapa empírica do estudo e está dividida em função dos dados coletados com os alunos entrevistados. O roteiro de entrevistas apresentava perguntas introdutórias sobre as ações inclusivas adotadas pelas universidades. Apesar de não tratarem especificamente dos incidentes críticos que influenciam na percepção da qualidade dos serviços da IES, observou-se que as respostas destes questionamentos estão 
diretamente relacionadas ao objetivo do presente estudo. Portanto, optou-se por dividir esta seção em três partes e abordar inicialmente as ações inclusivas das IES. Em seguida, os encontros de serviços nas IES e a vulnerabilidade do consumo são retratados e, por fim, a construção da percepção desfavorável sobre os serviços dos funcionários de secretaria e dos professores é apresentada.

\section{As ações inclusivas (ou exclusivas) das IES}

A construção da percepção desfavorável de uma IES pelos deficientes visuais está diretamente relacionada às ações inclusivas desenvolvidas por esta organização. Apesar da tendência de ampliação do processo de inclusão escolar nas universidades brasileiras, em diversos relatos ficou evidente a percepção dos alunos de que este processo se deve, sobretudo, aos instrumentos legais vigentes. Esta percepção é manifestada por alunos de instituições públicas e privadas, como pode ser visto nas declarações abaixo:

Às vezes parece que a gente tá estudando de favor. Não é todo mundo que atende bem os [deficientes] visuais, já fiquei sabendo que eles comentam que a gente só consegue entrar por causa das cotas (ELENA).

No máximo, eles dão desconto na mensalidade. [...] Já tentaram me enganar algumas vezes, mas fui bem educado por minha família e conheço as leis e portarias que estão ao meu lado, ao contrário deles [funcionários da IES], que só "fazem as coisas no empurrão". [...] Tem que colocar pressão e mostrar que a lei tá ao meu favor (JOÃO).

Apesar da similaridade nos relatos acima de alunos de instituições distintas, é notória a maior mobilização das instituições públicas em aprimorar a qualidade do ensino dos deficientes visuais, através da oferta de uma melhor estrutura inclusiva. Esta constatação é corroborada pelos relatos dos alunos de IES privadas, que foram mais incisivos ao manifestar as dificuldades enfrentadas nestas instituições. Dentre os problemas mencionados, a falta de um planejamento voltado especificamente para este público-alvo é citado como um dos maiores entraves. Em consonância com as constatações de Baker, Holland e KaufmanScarborough (2007), as universidades particulares parecem não considerar os deficientes visuais como potenciais clientes. O coordenador (do meu curso) é
esforçado, está sempre disponível para
me receber. Mas em todo o semestre eu
tenho os mesmos problemas. A calçada
é esburacada, os professores são mal-
educados... É difícil. Minha amiga da
federal tem colegas que incentivam ela,
aqui são poucos (CLÁUDIA).

Todo ano é a mesma conversa. Se fizessem metade do que já prometeram, já tava de bom tamanho. O computador com DOSVOX (sistema computacional adaptado para deficientes visuais) foi uma luta, o banheiro adaptado vivia trancado. Ninguém pensa no todo [...](JOÃO).

Nesse sentido, a realização de ações pontuais é uma das características marcantes das atividades desenvolvidas pelos gestores destas instituições voltadas para a inclusão de deficientes visuais, o que provocou uma série de críticas dos entrevistados. Já os alunos das IES públicas relataram que as dificuldades são diversas, embora sejam amenizadas por iniciativas institucionais de longo prazo voltadas para a inclusão e acessibilidade.

NaIESpública federalhá,inclusive,umnúcleodeeducação especial com impressoras em Braille, planejamento para reprodução de textos para os deficientes visuais e profissionais capacitados para melhorar a qualidade do ensino dos alunos com deficiência visual e auditiva. Além disso, são oferecidas bolsas de extensão para alunos que auxiliam os colegas com deficiência. Estes bolsistas, denominados de "alunos apoiadores", dedicam 20 horas semanais para acompanhar as atividades acadêmicas desenvolvidas dentro e fora da sala de aula de acordo com as necessidades inerentes a cada universitário. Essa iniciativa foi mencionada pelos entrevistados das universidades federais como fundamental para a permanência nas instituições.

\footnotetext{
Assim que entrei na XXX (IES Federal), me falaram do XXX (núcleo de educação especial) e conversei com o pessoal de lá. Eles são ótimos, a Paulinha (aluna apoiadora) começou a trabalhar comigo nesse semestre e tem sido uma benção em minha vida (ANA).
} 
O XXX (núcleo de educação especial) me dá um suporte essencial desde que foi criado. Além de imprimir tudo que eu preciso, já precisei da ajuda dos apoiadores em atividades que não eram da universidade e eles sempre foram uns amores [...]. Nessa semana mesmo precisei de ajuda para me inscrever em um concurso, deu tudo certo (DIANA).

Em detrimento da importância das ações institucionais de longo prazo voltadas para a inclusão dos alunos, alguns entrevistados relataram problemas no seu desenvolvimento: "Às vezes falta papel, tinta das impressoras. Dificulta bastante" (IOGO). A entrevistada Diana também informou que: "Depende muito da sorte. A gente não tem participação da escolha do aluno apoiador, então ficamos a mercê do pessoal do núcleo". Observa-se, portanto, que o desenvolvimento das ações inclusivas nas IES paraibanas ainda não é capaz de suprir as necessidades dos alunos com deficiência visual, embora exista um esforço para melhor atendê-los, principalmente nas instituições públicas. De fato, há uma série de melhorias a serem realizadas, como a aquisição de novos equipamentos especializados e materiais didáticos, adaptações na estrutura física das universidades e, principalmente, uma mudança de postura dos funcionários de secretaria e professores.

Estes problemas também foram relatados há quase uma década por Leite e Silva (2006), no contexto das IES de Minas Gerais, o que denota a persistência dos gestores educacionais em não desenvolver ações inclusivas que supram as necessidades dos alunos com deficiência. Dentre os problemas mencionados acima, a mudança de postura dos funcionários de secretaria e professores será discutida no tópico a seguir, onde os encontros de serviços e a vulnerabilidade de consumo serão abordados.

\section{Os encontros de serviços nas IES e a vulnerabilidade de consumo}

O objetivo desse tópico é apresentar os encontros de serviços mais recorrentes que os alunos com deficiência visual vivenciaram nas universidades e as situações onde a vulnerabilidade de consumo foi evidenciada, devido às características biofísicas e psicossociais dos entrevistados ou às condições externas.
Buscou-se inicialmente identificar, junto aos alunos, quais eram as situações em que o contato com os funcionários de secretaria ocorriam com maior frequência. A realização de matrícula, informações sobre o trancamento e aproveitamento de disciplinas e a emissão de documentos estão entre as situações em que os encontros de serviços ocorreram com mais frequência. De maneira geral, os funcionários de secretária contribuíram para a construção de uma percepção favorável pelos alunos. "Eles (funcionários da coordenação e do departamento) sempre me tratam bem. Tiram minhas dúvidas sem nenhum estresse" (FERNANDA).

Em contrapartida, dois incidentes demonstraram a vulnerabilidade dos alunos durante os encontros de serviços com os funcionários. Cláudia e João, alunos de IES particulares distintas, afirmaram que já foram alvos da falta de idoneidade de colaboradores das universidades, como os relatos abaixo demonstram:

\begin{abstract}
O difícil mesmo é encontrar um deles (profissionais de secretaria) de confiança. Já tive problema na matrícula de uma disciplina, um rapaz tentou até ganhar meu dinheiro [...]. Agora só vou lá com meu marido [...]. Disseram que iam demitir ele, mas ele ainda ta lá (CLAUDIA).

Lá eles dão um desconto na mensalidade por que eu só cego. Quando eu peço pra eles comprarem material, dizem que já dão o desconto pra isso mesmo. Absurdo. Isso quando "esquecem" de lançar o desconto na mensalidade [...]. Já pensei em trancar e tentar na XXX (IES Federal), mas decidir continuar... Já tenho amigos aqui também, ajuda muito (GUSTAVO).
\end{abstract}

Em função das limitações biofísicas dos alunos, evidenciou-se a desigualdade nas relações de troca entre as IES e os universitários. Além disso, estes centros educacionais demonstraram ser um ambiente que contribui para a ocorrência da vulnerabilidade durante o consumo, ao invés de serem espaços onde o conhecimento produzido e as ações institucionais dificultam o fenômeno.

Já em relação aos encontros de serviços com os professores, foi observado que, além da sala de aula, o contato entre aluno e professor por e-mail, portais acadêmicos e nos corredores são recorrentes e fundamentais para a satisfação dos alunos. 
Antes de começar as aulas já dá pra saber aqueles que vão ajudar e os que dificultam ou não sabem nada da nossa limitação. Eu gosto de mandar um e-mail e pedir para eles adiantarem o envio do material que vou precisar pra disciplina. Se forem grossos ou não responderem, já sei logo (IOGO).

Minha avaliação é muito positiva dos professores [...]. Me disseram que a melhoria se deve muito ao trabalho do prof. XXX (ex-coordenador do curso), uma excelente pessoa. Muito educado, sempre cumprimenta a gente... É realmente uma rara exceção (BRUNA).

No entanto, o preconceito dos docentes aliado ao despreparo para lidar com alunos deficientes visuais gerou uma série de incidentes críticos negativos, evidenciando a vulnerabilidade de consumo dos alunos.

O que eu realmente não gosto é quando começam a falar alto perto de mim ou fazem de conta que eu não tô na sala. Ficam passando as instruções pros outros pra depois eles me repassarem. Isso pra mim ta sendo o mais difícil, até ano passado (durante o ensino médio) não tinha esse problema (ELENA).

A gente reclama, faz abaixo-assinado, mas não adianta. Os "antigão" (professores mais experientes) não saem mais do curso. Já discuti com um deles por que me chamou de ceguinho e dificultou minha vida aqui, mas foi mesmo que nada (JOÃO).

A partir dos relatos apresentados, é notório o maior impacto das condições externas em detrimento das condições biofísicas nas situações de vulnerabilidade de consumo dos participantes da pesquisa. Em consonância com o modelo de Baker, Gentry e Rittenburg (2005), constatou-se que a discriminação, a estigmatização, a distribuição de recursos e os elementos físicos foram preponderantes para as situações de vulnerabilidade e ficou evidente que o entendimento de deficiência como um problema provocado por atitudes de outros e características do ambiente social (THOMAS, 2004) é inteiramente plausível.

\section{A avaliação dos serviços dos funcionários de secretaria e dos professores}

Ao avaliar a interação com os funcionários de secretaria e com os professores, diversas críticas foram apresentadas pelos entrevistados. A construção da percepção desfavorável, em diversos casos, foi iniciada já na realização da matrícula na IES. "A moça não tinha o menor preparo para atender um visual. Me chamou até de senhora de tanto despreparo. Não sabia nem o que é a escrita em Braille (BRUNA). Gustavo relatou que: "eles não tinha nenbuma preocupação em me atender, nada (...) já ia desistindo na matrícula, foi desastrosa”. Além dos incidentes motivados pela falha na distribuição de recursos, outros fatores ambientais novamente contribuíram para a percepção desfavorável sobre os serviços dos funcionários de secretaria, como a estigmatização e o preconceito.

\begin{abstract}
O sr. queria me tratar como uma bebê, além de ficar falando bem devagar e sem dirigir a palavra a mim. E é por que eu não completamente cega, imagine se fosse (...). Já me acostumei com isso nos outros locais, é bem comum. Mas na universidade foi novidade pra mim, no começo. (FERNANDA).
\end{abstract}

Outro aspecto ressaltado pelos entrevistados relacionase com o excesso de atenção oferecido por certos funcionários. O que, de fato, espera-se das IES é a prestação de um serviço de qualidade com as devidas adaptações para melhor atender os deficientes visuais. Ao invés disso, o "tratamento especial" oferecido por certos colaboradores foi criticado pelos alunos, como o relato acima demonstra.

No que diz respeito às interações entre alunos e professores, observa-se que o corpo docente das universidades é um dos principais responsáveis por incidentes críticos negativos. $\mathrm{O}$ despreparo para realizar adaptações pedagógicas, por exemplo, foi uma das queixas mais recorrentes entre os entrevistados, como se observa abaixo: 
Eu converso com o pessoal do departamento, converso com os professores... mas é difícil. Tem professor que ajuda bastante, mas a maioria escreve desenhos e não avisam (...). É simples, se for escrever uma chave ou um colchete, é só avisar. Parece simples, mas faz toda a diferença (JOÃO).

Em vez de colaborarem para a inclusão dos alunos com deficiência visual nas atividades educativas, os docentes acabaram impulsionando as situações de vulnerabilidade. Como os próprios relatos acima demonstram, pequenos ajustes na didática em sala de aula podem facilitar a assimilação do conteúdo pelos entrevistados. O envio prévio dos materiais impressos e a descrição detalhada das figuras desenhadas na lousa são duas sugestões apontadas pelos entrevistados.

Durante a realização de atividades comuns no dia-adia de uma IES, os professores demonstraram o seu despreparo para conduzir as aulas com estes alunos. Ao formar grupos para realização de trabalhos e durante o lançamento das notas referentes às atividades individuais, o preconceito dos docentes proporcionou a ocorrência dos episódios transcritos abaixo:

Na hora de formar os grupos é complicado. Se você não tiver um amigo na turma, o pessoal não ajuda (...). Mas os professores atrapalham mais ainda, pergunta com aquela voz de pena se alguém quer me colocar no grupo. Como se fosse uma caridade (GUSTAVO).

Já tive minha nota aumentada sem nenhuma justificativa. No começo achava legal, mas depois percebe como eu era tola. Se eles faziam isso, é por que não confiavam na minha capacidade (CLÁUDIA).

Outros alunos relataram situações constrangedoras motivadas por atitudes de docentes e alunos em sala de aula. No entanto, exemplos positivos também foram mencionados. A aproximação entre o professor e o aluno com deficiência visual, segundo alguns entrevistados, é uma das maneiras mais fáceis de acelerar a inclusão escolar. O que é esperado pelos entrevistados, de fato, é não haja um tratamento diferenciado dos demais alunos - nem mais brando, nem preconceituoso -, mas que o professor converse com o aluno e esteja aberto a sugestões e adaptações em sua didática. No sentido contrário, os relatos acima demonstram que os docentes também são responsáveis pela construção de uma percepção desfavorável sobre os serviços educacionais de uma IES.

Diante do exposto, foi constatado que a avaliação negativa pelos alunos é iniciada durante a matrícula dos alunos e reforçada durante os encontros de serviço subsequentes, principalmente durante os encontros com professores. As experiências de vulnerabilidade demonstram a ineficiência das universidades em promover a inclusão desses alunos, que lidam constantemente com o estigma de profissionais despreparados para atendê-los.

\section{Considerações finais}

O elevado número de pessoas com deficiência visual no Brasil e a importância de melhorar a qualidade do ensino público e privado para esse grupo de consumo são alguns dos fatores que motivaram a construção deste estudo, que teve por objetivo compreender a avaliação de estudantes deficientes visuais sobre os encontros de serviço com funcionários de secretaria e professores em Instituições de Ensino Superior (IES). A partir dos relatos de universitários paraibanos, essas interações foram descritas e a compreensão sobre a vulnerabilidade de consumo dos alunos foi ampliada, através da descrição de ações inclusivas e exclusivas das instituições de IES públicas e privadas.

Os encontros de serviço entre alunos com deficiência visual e funcionários de secretaria foram marcados pelo despreparo dos colaboradores, que demonstraram não compreender as limitações impostas pela deficiência e as adaptações necessárias à prestação de serviço adequada. Por esta razão, situações constrangedoras para esses alunos - que acentuam a sua vulnerabilidade de consumo - foram protagonizadas por funcionários que confundiram a deficiência visual com as demais deficiências; trataram os alunos com excesso de piedade; ou não possuíam conhecimentos básicos sobre os direitos da pessoa com deficiência.

Em relação aos encontros de serviço com docentes, percebeu-se que os diálogos entre professores e alunos em sala de aula, por e-mail, através de portais 
acadêmicos e nos corredores são recorrentes e fundamentais para a satisfação dos alunos. Entretanto, as falhas nos encontros também são constantes como aumentar as notas dos alunos com deficiência sem justificativa -, devido ao preconceito destes. De acordo com os relatos, pequenos ajustes na didática em sala de aula podem facilitar a assimilação do conteúdo pelos entrevistados, tais como o envio prévio dos materiais impressos e a descrição detalhada das figuras desenhadas na lousa são duas sugestões apontadas pelos entrevistados.

De maneira geral, percebeu-se que ambos são responsáveis pela percepção negativa dos alunos, uma vez que a estigmatização e a discriminação foi manifestada pelos dois grupos de colaboradores. A avaliação negativa dos alunos é um processo iniciado durante a matrícula dos alunos e reforçado durante a série de encontros de serviço vivenciados com os colaboradores dessas organizações, principalmente durante os encontros com professores, sejam eles durante as aulas ou não.

Constatou-se também que, no contexto investigado, o processo de inclusão escolar das IES públicas encontra-se mais avançado em relação às universidades particulares, uma vez que foram observadas nas universidades públicas iniciativas institucionais bem avaliadas pelos entrevistados, como o suporte oferecido pelos núcleos de educação especial e a contratação de alunos apoiadores. Entretanto, as falhas na operacionalização dessas iniciativas, decorridas da falta de materiais de consumo específicos para a impressão em Braille e da falta de recursos para manutenção dos projetos inclusivos, atrapalharam diretamente no processo de inclusão. Nas IES particulares, a realização de atividades pontuais e de curto-prazo é desenvolvida frequentemente por seus gestores, o que evidencia a dificuldade desses empresários em reconhecer os deficientes visuais como consumidores e realizar investimentos voltados para este público-alvo. O mesmo cenário de descrença no potencial de consumo desse grupo de consumo foi evidenciado em outros segmentos de mercado, como em restaurantes (FARIA; MOTTA, 2012) e supermercados (DAMASCENA; FARIA, 2013).

Fica nítido que a criação de portarias e decretos, por si só, não é suficiente para garantir a inclusão dos deficientes visuais nas universidades, pois o aumento do número de matrículas deste grupo de alunos não garante a sua inclusão nas IES. De fato, é necessária uma reflexão sobre o processo de inclusão escolar nas universidades brasileiras, uma vez que a academia parece ser incapaz de formar docentes preparados para educar a todos os alunos matriculados, como a lei determina. O cenário relatado nesse estudo assemelhase ao descrito por Leite e Silva (2006), relatado há quase uma década e em outra região do país, o que demonstra a lentidão do processo de inclusão dos alunos com deficiência visual.

Recomenda-se para futuras investigações que o processo de inclusão escolar seja observado com alunos de outras regiões e com outros tipos de deficiência. A vulnerabilidade de outros grupos de indivíduos enquanto consumidoras em IES também é uma interessante lacuna de pesquisa, como intercambistas, negros, índios e idosos. Além disso, são bem-vindos estudos voltados para a compreensão das experiências de vulnerabilidade de consumo dos deficientes visuais em outros setores empresariais.

\section{Referências}

ANDREASEN, A. R.; MANNING, J. The dissatisfaction and complaining behavior of vulnerable consumers. Journal of Consumer Satisfaction and Complaining Behavior, v. 3, p. 12-20, 1990.

BAKER, S. M. Consumer normalcy: understanding the value of shopping through narratives of consumers with visual impairments. Journal of Retailing, v. 82, n. 1, p. 37-50, 2006.

BAKER, S.; GENTRY J. W.; RITTENBURG, T. L. Building understanding of the domain of consumer vulnerability. Journal of Macromarketing, v. 25, n .2, p.1-12, 2005.

BAKER, S.; HOLLAND, J.; KAUFMANSCARBOROUGH, C. How consumers with disabilities perceive "welcome" in retail servicescapes: a critical incident study. Journal of Services Marketing. v. 21, p. 160-173, 2007.

BAKER, S.; STEPHENS, D.; HILL, R. Marketplace experiences of consumers with visual impairments: Beyond the Americans with Disabilities Act. Journal 
of Public Policy \& Marketing, v. 20, n. 2, 2001.

BANDEIRA, M. L. et al. Avaliação da Qualidade do Ensino de pós-graduação: elementos para construção e validação de um instrumento de pesquisa. In: ENANPAD, 22., 1998, Foz do Iguaço. Anais... Rio de Janeiro: ANPAD, 1998.

BARNES, C. MERCER, G. Disability. Key Concepts (Polity Press), 2003.

BATTAGLIA, D.; BORCHARDT, M. Análise do Processo de Recuperação de Serviços a partir das Reclamações dos Clientes: estudo de caso em três organizações. Revista Produção, v. 20, n. 3, p. 455470, 2010.

BITNER, M. J. Evaluating Service Encounters: the effects of physical surroundings and employee respondes. Journal of Marketing, v. 54, p. 69-82, 1990.

BRASIL. Decreto $n^{\circ}$ 5.296. Regulamenta as Leis nos 10.048, e 10.098. 02 de Dezembro de 2004. Disponível em: <http://www.planalto.gov.br/ ccivil_03/_ato2004-2006/2004/decreto/d5296. htm> Acesso em: 06 mai. 2014.

BRENKERT, G. G. Marketing and the Vulnerable. Business Ethics Quarterly, Special Issue, n. 1, p. 7-20, 1998.

CARVALHO-FREITAS, M. N. et al. Socialização organizacional de pessoas com deficiência. RAE (Impresso), v. 50, p. 264-275, 2010.

CARVALHO-FREITAS, M. N.; MARQUES, A. L. Pessoas com Deficiência e Trabalho: percepções de gerentes e pós-graduandos em Administração. Psicologia Ciência e Profissão, v. 29, p. 244-257, 2009.

DAMASCENA, E. Elementos Sensoriais em Supermercados: uma Investigação na Perspectiva Transformativa do Consumidor Junto a Pessoas com Deficiência Visual. 2013. Dissertação (Mestrado em Administração) - Programa de Pós-Graduação em Administração da Universidade Federal de Pernambuco (PROPAD/UFPE), Recife, 2013.
Forma: O Uso de Elementos Sensoriais na Busca para Reduzir a Vulnerabilidade de Consumidores com Deficiência Visual. In: EMA, 6., 2014, Gramado. Anais... Gramado: ANPAD, 2014.

DAMASCENA, E. O.; FARIAS, S. A. Os Elementos Sensoriais Em Supermercados: Um Estudo Junto A Pessoas Com Deficiência Visual Na Perspectiva Da Pesquisa Transformativa Do Consumidor. In: ENANPAD, 37., 2013, Rio de Janeiro. Anais... Rio de Janeiro: ANPAD, 2013.

DÍAZ, F. et al. Educação inclusiva, Deficiência e Contexto social: questões contemporâneas. 2009. Disponível em: <https://repositorio.ufba.br/ri/ bitstream/ufba/ 170/1/Educacao\%20Inclusiva. pdf>. Acesso em: 15 jun. 2014.

DUTRA, H. F; OLIVEIRA, P. A.; GOUVEIA, T. B. Avaliando a Qualidade de Serviço numa Instituição de Ensino Superior. In: ENANPAD, 22., 2002, Foz do Iguaçu. Anais... Foz do Iguaçu: ANPAD, 2002.

EDVARSSON, B. Service Breakdowns: A study of Critical Incidents in na Air-Line. Internacional Journal of Service Industry Management, v. 3, n. 4, p. 17-29, 1992.

FARIAS, M. D. Pessoas com Deficiência Visual e Consumo em Restaurantes: Um Estudo Utilizando Análise Conjunta. 2010. Dissertação (Mestrado em Administração) - Programa de Pós-Graduação em Administração da Pontifícia Universidade Católica (PUC-Rio), Rio de Janeiro, 2010.

FARIA, M. D.; MOTTA, P. C. Pessoas com Deficiência Visual: barreiras para o turismo de lazer. Revista Turismo em Análise, v. 23, p. 691-717, 2012.

FARIA, M.; VERGARA, S.; CARVALHO, J. Pesquisas com Foco em Pessoas com Deficiências: Uma Reflexão a Partir de Paradigmas e Perspectivas Epistemológicas. In: EnEPQ, 3., 2011, João Pessoa. Anais... João Pessoa: ANPAD, 2011.

FLANAGAN, J. The Critical Incident Technique. Psychological Bulletin, v. 51, n. 4, p. 28-40, 1954.

DAMASCENA, E. O Supermercado Visto de Outra 
FROEMMING, L. Encontros de Serviços em uma Instituição de Ensino Superior. 2001. Tese (Doutorado em Administração) - Programa de Pós-Graduação em Administração da Universidade Federal do Rio Grande do Sul (PPGA/UFRGS), Porto Alegre, 2001.

FUNDAÇÃO DORINA NOWILL. Relatório Anual de Atividades, 2012. Disponível em: < http://www. fundacaodorina.org.br/uploads/relatorios-anuais/ relatorio_anual_2012.doc> Acesso em: 04 abr. 2014.

GOODRICH, K.; RAMSEY, R. Are Consumers with Disabilities Receiving the Services They Need? Journal of Retailing and Consumer Services, 19, 88-97, 2012.

HOGG, G.; WILSON, E. Does he take sugar? The disabled consumer and identity. British Academy of Management Conference Proceedings. St. Andrews, 2004.

JONES, J. L.; MIDDLETON, K. L. Ethical Decision-Making by Consumers: The Roles of Product Harm and Consumer Vulnerability. Journal of Business Ethics, v. 70, p. 247-264, 2007.

LEITE, C. G. Educação Inclusiva: Braille. Rio de Janeiro: Universidade Castelo Branco (UCB), 2009. Disponível em: <http://ucbweb2.castelobranco. br/webcaf/arquivos/ped agogia/6_pe riodo/ Educacao_I nclusiva_Braille.pdf > Acesso em: 19 abr. 2014.

LEITE, M. R.; SILVA, G. R. Inclusão da Pessoa com Deficiência Visual nas Instituições de Educação Superior de Belo Horizonte. In: ENANPAD, 30, 2006. Anais... Salvador: ANPAD, 2006.

KAUFMAN-SCARBOROUGH, C.; Accessible Advertising for Visually-Disabled Persons: the case of color-deficient consumers. Journal of Consumer Marketing, v. 18, n. 4, p. 303- 318, 2001.

KOTLER, P.; FOX, K. Marketing Estratégico para Instituições Educacionais. Editora Atlas: São Paulo, 1994.

LIZOTE, S. A.; VERDINELLI, M. A. Processo de Ensino Aprendizagem Universitário: um
Estudo sobre Educação Inclusiva de Alunos com Necessidades Especiais Auditivas. In: ENANPAD, 36., 2012, Rio de Janeiro. Anais... Rio de Janeiro: ANPAD, 2012.

LOVELOCK, C. H. Classifying services do gain strategic marketing insights. Journal of Marketing, v. 48, p. 9-20, 1983.

MANENTE, M.; RODRIGUES, O.; PALAMIN, M. Deficientes auditivos e escolaridade: fatores diferenciais que possibilitam o acesso ao ensino superior. Revista Brasileira de Educação Especial, n. 1, v.13, p. 27-42, 2007.

MANO, R. F. Consumidor com Deficiência: Implicações de Fatores Pessoais e Contextuais no Consumo em Redes Varejistas de João Pessoa/PB. 2014. Dissertação (Mestrado em Administração) Programa de Pós-Graduação em Administração da Universidade Federal da Paraíba (PPGA/UFPB), João Pessoa, 2014.

MANTOAN, M. T. Inclusão Escolar: o que é? Por quê? Como fazer? São Paulo: Moderna, 2003.

MERRIAM, S. B. Qualitative research: a guide to design and implementation. New York: Jossey-Bass, 2009.

MOREIRA, L. et al. O trabalho para os portadores de necessidades especiais: um caminhar pela diversidade através dos conceitos de poder, minoria e deficiência. In: Encontro de Gestão de Pessoas e Relações de Trabalho, 2., 2009. Anais... Curitiba: ANPAD, 2009.

MOREIRA, M. et al. Percepção de clientes em encontros de serviços: Um olhar sobre os atributos intangíveis do atendimento. Rev. Portuguesa e Brasileira de Gestão, v. 10, n. 1-2, 2011.

NEPOMUCENO, M. F.; CARVALHO-FREITAS, M. N. As crenças e percepções dos gerentes e as possibilidades de trabalho das pessoas com deficiência. Psicologia em Pesquisa, v. 2, p. 81-94, 2008.

ORGANIZAÇÃO MUNDIAL DA SAÚDE (OMS). Relatório mundial sobre a deficiência. São Paulo: SEDPcD, 2011. Disponível em: <http://whqlibdoc. 
who.int/pu blications/2011/9788564047020_por. pdf > Acesso em: 23 mai. 2014.

PARASURAMAN, A., ZETHAML,V. A., BERRY, L. A conceptual model of service quality and its implications for future research. Journal of Marketing, p. 44, Fall 1985.

PAVIA, T. M.; MASON, M. M. Vulnerability and Physical, Cognitive and Behavioral Impairment: Model Extensions and Open questions. Journal of Macromarketing. v. 18, 2014.

PINTO, M.; FREITAS, R. O que os Olhos não Veem o Coração Não Sente? Investigando Experiências de Compra de Deficientes Visuais no Varejo de Roupas. In: ENANPAD, 35. Anais... Rio de Janeiro: ANPAD, 2011.

SHULTZ II, C. J.; HOLBROOK, M. B. The Paradoxical Relationships Between Marketing and Vulnerability. Journal of Public Policy \& Marketing, v. 28, n.1, p. 124-127, 2009.

SILVA, A. P. Ser ou não Ser? Eis a Questão: Uma Investigação sobre a Vulnerabilidade dos Consumidores. 2011. Dissertação (Mestrado em Administração) - Programa de Pós-Graduação em Administração da Universidade Federal da Paraíba (PPGA/UFPB), João Pessoa, 2011.

SOLOMON, M. R. et al. A Role Theory Perspective on Dyadic Interactions: The Service Encounter. Journal of Marketing, v. 49, p. 99-111, 1985.

THOMAS, C. How is disability understood? An examination of sociological approaches. Disability \& Society, v. 19, n. 6, p. 569-583, 2004.

\section{XAVIER, A. C. A Gestão da Qualidade e a}

Excelência dos Serviços Educacionais: custos e benefícios de sua implantação. Brasília: IPEA, 1996. Disponível em: <http://www.bndes.gov. br/SiteBNDES/export/sites/default/bndes_pt/ Galerias/Arquivos/bf_bancos/e0000529.pdf> Acesso em: 14 abr. 2014.

WILKIE, W. L.; MOORE, E. S. Scholarly research in marketing: Exploring the "4 eras" of thought development. Journal of Public Policy and Marketing, v. 22, p. 116-146, 2003.
WORLD HEALTH ORGANIZATION (WHO). Towards a Common Language for Functioning, Disability and Health. Geneva, 2002. Disponível em: <http://www.who.in t/classifications/icf/training/ icfbeginnersguide.pdf> Acesso em: 13 mar. 2014. 